\title{
RESEARCH
}

Open Access

\section{Risk modifiers of acute respiratory distress syndrome in patients with non-pulmonary sepsis: a retrospective analysis of the FORECAST study}

Hiroki Iriyama ${ }^{1}$, Toshikazu Abe ${ }^{1,2,3^{*}}$, Shigeki Kushimoto ${ }^{4}$, Seitaro Fujishima ${ }^{5}$, Hiroshi Ogura ${ }^{6}$, Atsushi Shiraishi ${ }^{7}$, Daizoh Saitoh $^{8}$, Toshihiko Mayumi ${ }^{9}$, Toshio Naito ${ }^{1}$, Akira Komori ${ }^{1}$, Toru Hifumi ${ }^{10}$, Yasukazu Shiino ${ }^{11}$, Taka-aki Nakada ${ }^{12}$, Takehiko Tarui ${ }^{13}$, Yasuhiro Otomo ${ }^{14}$, Kohji Okamoto ${ }^{15}$, Yutaka Umemura ${ }^{6}$, Joji Kotani ${ }^{16}$, Yuichiro Sakamoto ${ }^{17}$, Junichi Sasaki ${ }^{18}$, Shin-ichiro Shiraishi ${ }^{19}$, Kiyotsugu Takuma ${ }^{20}$, Ryosuke Tsuruta ${ }^{21}$, Akiyoshi Hagiwara ${ }^{22}$, Kazuma Yamakawa ${ }^{23}$, Tomohiko Masuno ${ }^{24}$, Naoshi Takeyama ${ }^{25}$, Norio Yamashita ${ }^{26}$, Hiroto Ikeda ${ }^{27}$, Masashi Ueyama ${ }^{28}$, Satoshi Fujimi ${ }^{23}$, Satoshi Gando ${ }^{29,30}$ and on behalf of JAAM FORECAST group

\begin{abstract}
Background: Predisposing conditions and risk modifiers instead of causes and risk factors have recently been used as alternatives to identify patients at a risk of acute respiratory distress syndrome (ARDS). However, data regarding risk modifiers among patients with non-pulmonary sepsis is rare.

Methods: We conducted a secondary analysis of the multicenter, prospective, Focused Outcomes Research in Emergency Care in Acute Respiratory Distress Syndrome, Sepsis and Trauma (FORECAST) cohort study that was conducted in 59 intensive care units (ICUs) in Japan during January 2016-March 2017. Adult patients with severe sepsis caused by non-pulmonary infection were included, and the primary outcome was having ARDS, defined as meeting the Berlin definition on the first or fourth day of screening. Multivariate logistic regression modeling was used to identify risk modifiers associated with ARDS, and odds ratios (ORs) and their 95\% confidence intervals were reported. The following explanatory variables were then assessed: age, sex, admission source, body mass index, smoking status, congestive heart failure, chronic obstructive pulmonary disease, diabetes mellitus, steroid use, statin use, infection site, septic shock, and acute physiology and chronic health evaluation (APACHE) II score.
\end{abstract}

Results: After applying inclusion and exclusion criteria, 594 patients with non-pulmonary sepsis were enrolled, among whom 85 (14.3\%) had ARDS. Septic shock was diagnosed in 80\% of patients with ARDS and 66\% of those without ARDS $(p=0.01)$. APACHE II scores were higher in patients with ARDS [26 (22-33)] than in those without ARDS [21 (1628), $p<0.01]$. In the multivariate logistic regression model, the following were independently associated with ARDS: ICU admission source [OR, 1.89 (1.06-3.40) for emergency department compared with hospital wards], smoking status [OR, 0.18 (0.06-0.59) for current smoking compared with never smoked], infection site [OR, 2.39 (1.04-5.40) for soft tissue infection compared with abdominal infection], and APACHE II score [OR, 1.08 (1.05-1.12) for higher compared with lower score].

(Continued on next page)

\footnotetext{
*Correspondence: abetoshi111@gmail.com

'Department of General Medicine, Juntendo University, 2-1-1 Hongo, 103

Bunkyo-ku, Tokyo 113-0033, Japan

${ }^{2}$ Health Services Research and Development Center, University of Tsukuba,

Tsukuba, Japan

Full list of author information is available at the end of the article
}

(c) The Author(s). 2020 Open Access This article is distributed under the terms of the Creative Commons Attribution 4.0 International License (http://creativecommons.org/licenses/by/4.0/), which permits unrestricted use, distribution, and reproduction in any medium, provided you give appropriate credit to the original author(s) and the source, provide a link to the Creative Commons license, and indicate if changes were made. The Creative Commons Public Domain Dedication waiver (http://creativecommons.org/publicdomain/zero/1.0/) applies to the data made available in this article, unless otherwise stated. 
(Continued from previous page)

Conclusions: Soft tissue infection, ICU admission from an emergency department, and a higher APACHE II score appear to be the risk modifiers of ARDS in patients with non-pulmonary sepsis.

Keywords: Acute respiratory distress syndrome, acute respiratory failure, sepsis

\section{Background}

Acute respiratory distress syndrome (ARDS) comprises heterogenous clinical conditions. Reportedly, the prognosis of ARDS is poor [1, 2], and once a patient develops ARDS, treatment options are limited to only a few supportive strategies [3-9], making it important to identify patients at a high risk of ARDS [10]. Previous studies have reported a variety of causes and risk factors of ARDS [1, 11]; however, there is a lack of clarity between these because only a small proportion of patients with these causes and risk factors develop ARDS [12, 13]. Therefore, alternative efforts have been recently focusing on the roles of two types of risk factors: predisposing conditions and risk modifiers $[14,15]$. Predisposing conditions are preceding acute pathophysiological events, such as sepsis. Risk modifiers include obesity $[15,16]$, smoking status $[15,17,18]$, diabetes mellitus (DM) (reduced risk modifier) [14, 15, 19], glucocorticoids [20], statin [21, 22], non-pulmonary infection (reduced risk modifier) [13, 23], shock [13, 15], tachypnea [14, 15], oxygen supplementation [15, 24], hematocrit [11], hypoalbuminemia [14, 15], acidemia [11, 15], and disease severity $[2,11,13]$. There is a possibility that ARDS may be precisely predicted using a combination of predisposing conditions and risk modifiers.

ARDS has been associated with two major pathophysiologic changes in various proportions. One is the influx of protein-rich effusion to the alveolar space caused by the damage of the local alveolar epithelium and another is leakage to the pulmonary interstitium through the capillary endothelium caused by systemic inflammation. Direct ARDS is associated with higher impairment of alveolar epithelium and lower impairment of capillary endothelium than indirect ARDS [23, 25]. Thus, we think risk modifiers of direct and indirect ARDS should be discussed separately.

Indeed to date, however, little has been reported about risk modifiers for ARDS among patients with nonpulmonary sepsis because a large proportion of patients with pulmonary sepsis have been included in previous studies about risk modifiers $[2,14,15]$.

We aimed to evaluate the risk modifiers associated with indirect ARDS among patients with non-pulmonary sepsis.

\section{Methods}

\section{Design and setting}

We conducted a secondary analysis of the sepsis cohort in the Focused Outcomes Research in Emergency Care in Acute Respiratory Distress Syndrome, Sepsis, and Trauma (FORECAST) study. This was a multicenter prospective cohort study of 1184 patients with severe sepsis or septic shock enrolled from 59 Intensive care units (ICUs) in Japan and conducted from January 2016 to March 2017 [26].

\section{Participants}

We included adult patients from the FORECAST database if they were aged $\geq 16$ years and had severe sepsis or septic shock caused by non-pulmonary infection. The exclusion criteria were patients with missing data of the first or fourth days of ARDS screening in this study.

\section{Data collection}

Patient information was obtained from the FORECAST database, including demographic data, admission source, comorbidities, infection sites, sepsis-related severity scores, and laboratory data. Data collection was performed as part of the routine clinical workup by the original FORECAST investigators.

\section{Data definitions}

ARDS was diagnosed if present on the first or fourth day of ARDS screening, according to the Berlin ARDS definition [27]. Severe sepsis and septic shock were defined based on the sepsis-2 criteria [28]. Non-pulmonary infection was defined as infection other than pneumonia or empyema. Cases of DM with and without end-organ complications were reported as comorbidities. Also, "ventilator-free days" was defined as the number of days within the first 28 days after enrolment, during which a patient was able to breathe without the help of a ventilator. Patients who died during the study were assigned a ventilator-free day of 0 . ICU-free days were calculated and scored in a similar manner [29].

\section{Statistical analysis}

Patients were stratified into groups with and without ARDS (i.e., ARDS and No ARDS groups). Descriptive statistics were calculated as proportions for categorical variables and as medians (interquartile range [IQR]) or mean \pm standard deviation (SD) for continuous variables, where appropriate. Statistical differences between two groups were evaluated by univariate analyses, using the chi-square or Fisher exact tests for categorical variables and the Mann-Whitney $U$ test for continuous 
variables because the data did not have a normal distribution.

To identify the risk modifiers correlated with having ARDS in patients with non-pulmonary sepsis, we developed a multivariate logistic regression model and reported odds ratios (ORs) with their 95\% confidence intervals (CIs). We hypothesized that there could be different risk modifiers for indirect ARDS compared with those for direct ARDS reported in previous studies. The primary outcome of interest was having ARDS, and the explanatory variables were selected based on previous research: body mass index, smoking status, DM, glucocorticoids, statin, site of infection, septic shock, and acute physiology and chronic health evaluation II (APACHE II) score. We also include clinically relevant explanatory variables, such as age, gender, admission source, and coexisting conditions (e.g., congestive heart failure and chronic obstructive pulmonary disease). However, we did not take variables such as tachypnea, oxygen supplementation, acidosis, and hypoalbuminemia into the logistic regression model because these possible risk modifiers might result from ARDS. Finally, the non-pulmonary Sequential Organ Failure Assessment (SOFA) score was used in a sensitivity analysis.

All $p$ values were two-sided, with $p$ values $<0.05$ considered statistically significant. All statistical analyses were performed using the EZR software (Version 1.32) [30].

\section{Results}

Of the 1184 patients with severe sepsis in the FORECAST study, 817 with non-pulmonary infection were eligible for this study. Another 85 patients were excluded because they had missing data of the first day of ARDS screening. This left a cohort of 69 patients with ARDS and 663 without ARDS on the first day of screening. Of those without ARDS, 35 died on the second or third day and 103 patients had missing data of the fourth day of ARDS screening, so were excluded. Finally, 594 patients with non-pulmonary sepsis were enrolled, among whom 85 (14.3\%) had ARDS at the first or fourth day of ARDS screening (the ARDS group) (Fig. 1)

\section{Baseline characteristics}

The median age was 72 (IQR: 62-81) years and males accounted for 340 patients (57.2\%). There were 231 patients (38.9\%) with abdominal infection, 147 (24.7\%) with urinary tract infection, and 91 (15.3\%) with soft tissue infection. The baseline characteristics are compared between patients with and without ARDS in Table 1.

Patients with ARDS had a lower Charlson Comorbidity Index than patients without ARDS, but there were no significant differences between the groups regarding other baseline characteristics, such as age, gender, and admission source. There was no significant difference between patients with and without ARDS regarding previously known risk modifiers for direct and indirect ARDS, including body mass index, DM, smoking status, and site of infection. A higher proportion of patients had septic shock with ARDS (80\%) than without ARDS (66\%; $p=0.02)$. Compared to those without ARDS, patients with ARDS had higher severity scores assessed by the APACHE II (26 vs. $21, p<0.001)$ and Non-pulmonary SOFA ( 9 vs. $7, p<0.001)$.

\section{Outcomes in patients with ARDS}

In-hospital mortality in patients with and without ARDS was $29.9 \%$ and $16.5 \%$, respectively $(p=0.007$ ) (Table 2 ).

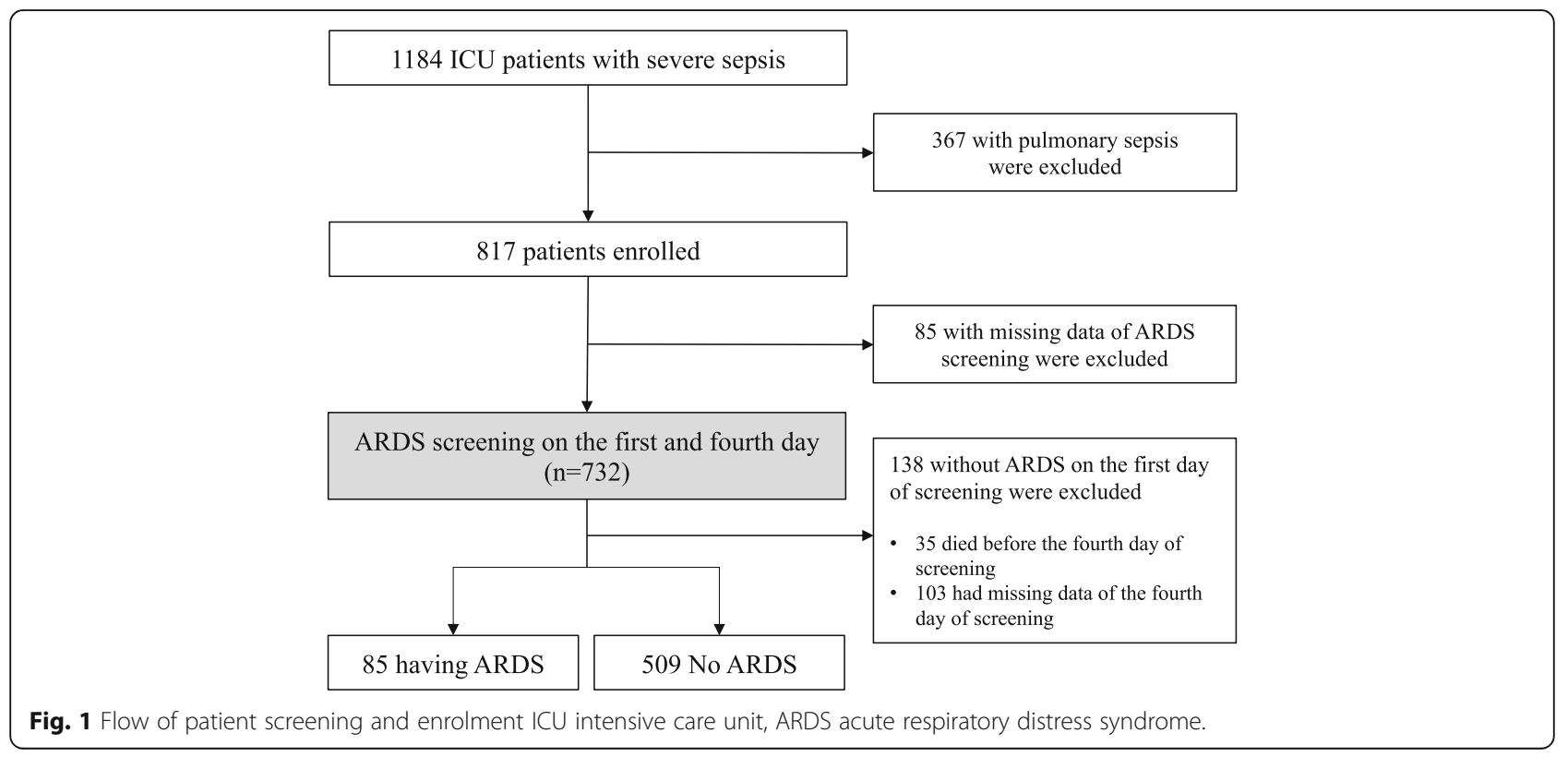


Table 1 Demographic, infection, and admission characteristics comparing those had ARDS and those did not

\begin{tabular}{|c|c|c|c|c|}
\hline Characteristics & & $\operatorname{ARDS}(n=85)$ & No ARDS $(n=509)$ & $P$ value \\
\hline Age at admission-year & & $70(62-80)$ & $72(63-82)$ & 0.46 \\
\hline Male gender & & $51(60)$ & $289(56.8)$ & 0.66 \\
\hline Admission source & Hospital wards and other hospitals & $28(32.9)$ & $226(44.5)$ & 0.12 \\
\hline & Emergency department & $52(61.2)$ & $255(50.2)$ & \\
\hline & Intensive care unit & $5(5.9)$ & $27(5.3)$ & \\
\hline Body mass index- $\mathrm{kg} / \mathrm{m}^{2}$ & & $23.4 \pm 4.82$ & $23.4 \pm 5.45$ & 0.07 \\
\hline Coexisting conditions & Myocardial infarction & $5(5.9)$ & $27(5.3)$ & 0.80 \\
\hline & Congestive heart failure & $9(10.6)$ & $53(10.4)$ & 1.00 \\
\hline & Peripheral vascular disease & $2(2.4)$ & $10(2)$ & 0.69 \\
\hline & Cerebrovascular disease & $7(8.2)$ & $65(12.8)$ & 0.31 \\
\hline & Dementia & $4(4.7)$ & $44(8.6)$ & 0.28 \\
\hline & COPD & $4(4.7)$ & $25(4.9)$ & 1.00 \\
\hline & Connective tissue disease & $5(5.9)$ & $32(6.3)$ & 1.00 \\
\hline & Peptic ulcer disease & $2(2.4)$ & $17(3.3)$ & 1.00 \\
\hline & Diabetes mellitus & $21(24.7)$ & $121(23.8)$ & 0.96 \\
\hline & Chronic kidney disease & $5(5.9)$ & $39(7.7)$ & 0.66 \\
\hline & Hemiplegia & $2(2.4)$ & $20(3.9)$ & 0.76 \\
\hline & Malignancy (solid) & $6(7.1)$ & $68(13.4)$ & 0.15 \\
\hline & Malignancy (blood) & $1(1.2)$ & $9(1.8)$ & 1.00 \\
\hline & Metastatic tumor & $2(2.4)$ & $15(2.9)$ & 1.00 \\
\hline & Mild liver disease & $3(3.5)$ & $25(4.9)$ & 0.78 \\
\hline & Moderate to severe liver disease & $0(0)$ & $15(2.9)$ & 0.15 \\
\hline & AIDS & $0(0)$ & $1(0.2)$ & 1.00 \\
\hline CCI w/o diabetes mellitus & & $0(0-1)$ & $1(0-2)$ & 0.004 \\
\hline Smoking & Never & $55(66.3)$ & $275(59.0)$ & 0.05 \\
\hline & Former & $24(28.9)$ & $123(26.4)$ & \\
\hline & Current & $4(4.8)$ & $68(14.6)$ & \\
\hline Regular medication & Glucocorticoids & $9(10.6)$ & 69 (13.6) & 0.56 \\
\hline & Immunosuppressants & $3(3.5)$ & $21(4.1)$ & 1.00 \\
\hline & Anticoagulant & $13(15.3)$ & $42(8.3)$ & 0.04 \\
\hline & Antiplatelet & $14(16.5)$ & $87(17.1)$ & 1.00 \\
\hline & Statin & $5(5.9)$ & $53(10.4)$ & 0.24 \\
\hline & Beta blocker & $5(5.9)$ & $36(7.1)$ & 0.82 \\
\hline & Anticancer drug & $2(2.4)$ & $15(2.9)$ & 1.00 \\
\hline & Antibiotics & $16(18.8)$ & $70(13.8)$ & 0.29 \\
\hline Site of infection & Abdomen & $32(37.6)$ & $199(39.1)$ & 0.25 \\
\hline & Urinary tract & $15(17.6)$ & $132(25.9)$ & \\
\hline & Soft tissue & $17(20.0)$ & $74(14.5)$ & \\
\hline & Other than abdomen, urinary tract, or soft tissue & $21(24.7)$ & $104(20.4)$ & \\
\hline Septic shock & & $68(80)$ & $336(66)$ & 0.02 \\
\hline Respiratory rate- $/$ min & & $25(22-32)$ & $24(21-30)$ & 0.34 \\
\hline $\mathrm{FiO}_{2}$ & & $0.4(0.3-0.5)$ & $0.3(0.25-0.4)$ & $<0.001$ \\
\hline $\mathrm{PaO}_{2}-\mathrm{mmHg}$ & & $83(75-103)$ & $94(78.6-112)$ & 0.05 \\
\hline $\mathrm{PaO}_{2} / \mathrm{FiO}_{2}$ ratio & & 179 (119-240) & $284(184-374)$ & $<0.001$ \\
\hline
\end{tabular}


Table 1 Demographic, infection, and admission characteristics comparing those had ARDS and those did not (Continued)

\begin{tabular}{|c|c|c|c|c|}
\hline \multicolumn{2}{|l|}{ Characteristics } & $\operatorname{ARDS}(n=85)$ & No ARDS $(n=509)$ & $P$ value \\
\hline \multicolumn{2}{|l|}{ Hematocrit—\% } & $33(28-38)$ & $33(29-39)$ & 0.38 \\
\hline \multicolumn{2}{|l|}{ Serum albumin—g/dL } & $2.4(2.0-2.8)$ & $2.6(2.2-3.2)$ & 0.01 \\
\hline \multicolumn{2}{|l|}{ Blood pH } & $7.36(7.29-7.44)$ & $7.41(7.34-7.47)$ & 0.003 \\
\hline \multicolumn{2}{|l|}{ Positive blood culture } & $54(63.5)$ & $303(59.9)$ & 0.53 \\
\hline \multirow[t]{2}{*}{ Pathogens (blood culture) } & Gram positive coccus & $23(27.1)$ & $116(22.8)$ & 0.39 \\
\hline & Gram negative rod & $28(32.9)$ & $167(32.8)$ & 0.98 \\
\hline \multicolumn{2}{|l|}{ APACHE II score } & $26(21-33)$ & $21(16-28)$ & $<0.001$ \\
\hline \multicolumn{2}{|l|}{ Non-pulmonary SOFA score } & $9(7-11)$ & $7(4-9)$ & $<0.001$ \\
\hline
\end{tabular}

Reported counts (proportions) for categorical variables and median (interquartile range) for continuous variables

$A R D S$ acute respiratory distress syndrome defined by Berlin criteria, COPD chronic obstructive pulmonary disease, $A I D S$ acquired immune deficiency syndrome, CCI Charlson Comorbidity Index, $\mathrm{FiO}_{2}$ fraction of inspiratory oxygen, $\mathrm{PaO}_{2}$ partial pressure of oxygen in arterial blood, APACHE II acute physiology and chronic health evaluation II, SOFA sequential organ failure assessment

Definition of categorical variables: other than abdomen, urinary tract, or soft tissue = central nervous system, intravenous catheter, osteoarticular, endocardium, wound, implant device, and others; positive blood culture = culture without clinically confirmed contamination; Gram-positive coccus = Staphylococcus,

Streptococcus, and Enterococcus; Gram-negative rod = Acinetobacter, Aeromonas, Burkholderia, Citrobacter, Escherichia, Enterobacter, Haemophilus, Klebsiella, Legionella, Pseudomonas, Proteus, Salmonella, Serratia, Stenotrophomonas, and Vibrio

Missing data (due to missing data of each outcome measures): admission source $=1 ;$ body mass index $=9 ;$ smoking $=45 ;$ respiratory rate $=1 ; \mathrm{FiO}_{2}=14 ; \mathrm{PaO}{ }_{2}=$ $18 ; \mathrm{PaO}_{2} / \mathrm{FiO}_{2}$ ratio $=19$; serum albumin $=10$; blood $\mathrm{pH}=14$; positive blood culture $=3 ;$ APACHE II score $=53$; non-pulmonary SOFA score $=46$

Of the 404 patients with septic shock, the in-hospital mortality rate of those with ARDS was significantly higher than that of patients without ARDS $(32.8 \%$ vs. $17.9 \%, p=$ 0.01 ). The median ventilator-free days for patients with ARDS was less than that for patients without ARDS (15 [0-21] vs. 22 [9-28], $p<0.001)$, as was the median ICUfree days (14 [4-19] vs. 19 [10-24], $p<0.001)$. However, there was no significant difference in the length of hospital stay by ARDS status (25 [11-61] vs. $26[15-51], p=0.39)$. In terms of survivor dispositions, a larger proportion of patients with ARDS than without ARDS needed to be transferred to other facilities.

\section{Risk modifiers for having ARDS}

In the multivariate logistic regression model, we identified three main risk modifiers associated with having ARDS (Table 3). Notably, the odds of having ARDS were higher for patients from the emergency department than for those transferred from hospital wards or other hospitals (OR, 1.89 [1.06-3.40]), for patients with soft tissue infection than for those with abdominal infection (OR, 2.37 [1.04-5.40]), and for those with a higher APACHE II score (OR, 1.08 [1.05-1.12]).

\section{Discussion}

In this retrospective cohort study of patients with nonpulmonary sepsis, admission route (from the emergency department rather than wards or other hospitals), disease severity (a higher APACHE II score), and infection site (soft tissue rather than abdominal infection) were risk modifiers for non-pulmonary septic ARDS. However, obesity, DM, statins, glucocorticoids, and shock were not statistically associated with ARDS.

Duration of onset from infection could be a valid risk modifier of ARDS in non-pulmonary sepsis. In our results, admission from the emergency department was

Table 2 Outcomes comparing patients with and without ARDS among patients with non-pulmonary sepsis

\begin{tabular}{|c|c|c|c|c|}
\hline Variable & & $\operatorname{ARDS}(n=85)$ & No ARDS $(n=509)$ & $P$ value \\
\hline \multirow[t]{3}{*}{ In-hospital mortality } & & $23(29.9)$ & $84(16.5)$ & 0.007 \\
\hline & with septic shock $(n=404)$ & $20(32.8)$ & $60(17.9)$ & 0.01 \\
\hline & Without septic shock $(n=190)$ & $3(18.8)$ & $24(13.9)$ & 0.71 \\
\hline \multirow{2}{*}{$\begin{array}{l}\text { Survivor dispositions } \\
(n=479)\end{array}$} & Home & $10(18.5)$ & $157(36.9)$ & \multirow[t]{2}{*}{0.006} \\
\hline & Transfer & $44(81.5)$ & $268(63.1)$ & \\
\hline ICU-free days & & $14(3.75-19.25)$ & $19(10-24)$ & $<0.001$ \\
\hline Ventilator-free days & & $15(0-21)$ & $22(8.75-28)$ & $<0.001$ \\
\hline Length of hospital stay & & $25(11-61)$ & $26(15-51)$ & 0.35 \\
\hline
\end{tabular}

Reported counts (proportions) for categorical variables and median (interquartile range) for continuous variables

ARDS acute respiratory distress syndrome, ICU intensive care unit

Missing data (due to missing data of each outcome measures): in-hospital mortality $=8$; survivor dispositions $=0$; ICU-free days $=89 ;$ ventilator-free days $=9$;

length of hospital stay $=8$ 
Table 3 Multivariable analysis for having ARDS associated with non-pulmonary sepsis $(n=594)$

\begin{tabular}{|c|c|c|c|}
\hline Variable & & Odds ratio $(95 \% \mathrm{Cl})$ & $P$ value \\
\hline Age at admission - per year & & $0.99(0.97-1.01)$ & 0.29 \\
\hline Male gender & & $1.33(0.71-2.49)$ & 0.37 \\
\hline \multirow[t]{3}{*}{ Admission source } & Hospital wards and other hospitals & Reference & \\
\hline & Emergency department & $1.89(1.06-3.40)$ & 0.03 \\
\hline & Intensive care unit & $0.96(0.25-3.65)$ & 0.95 \\
\hline Body mass index- $\mathrm{kg} / \mathrm{m}^{2}$ & & $1.04(0.98-1.09)$ & 0.19 \\
\hline \multirow[t]{3}{*}{ Smoking } & Never & Reference & \\
\hline & Former & $0.77(0.39-1.54)$ & 0.46 \\
\hline & Current & $0.18(0.06-0.59)$ & 0.004 \\
\hline \multirow[t]{3}{*}{ Coexisting conditions } & Congestive heart failure & $0.72(0.26-1.88)$ & 0.50 \\
\hline & COPD & $1.54(0.46-5.21)$ & 0.49 \\
\hline & Diabetes mellitus & $0.69(0.35-1.37)$ & 0.29 \\
\hline \multirow[t]{2}{*}{ Regular medication } & Glucocorticoids & $0.48(0.19-1.22)$ & 0.12 \\
\hline & Statin & $0.36(0.10-1.24)$ & 0.11 \\
\hline \multirow[t]{4}{*}{ Site of infection } & Abdomen & Reference & \\
\hline & Urinary tract & $0.71(0.33-1.55)$ & 0.39 \\
\hline & Soft tissue & $2.37(1.04-5.40)$ & 0.04 \\
\hline & Other than abdomen, urinary tract, or soft tissue & $1.57(0.74-3.32)$ & 0.24 \\
\hline Septic shock & & $1.43(0.74-2.78)$ & 0.29 \\
\hline APACHE II score-per point & & $1.08(1.05-1.12)$ & $<0.001$ \\
\hline
\end{tabular}

related to having ARDS, and it is possible that both direct and indirect ARDS developed soon after or at the onset of sepsis $[15,31]$. Thus, ARDS may not have occurred after time had passed from admission, and further studies are needed to investigate the timing of the onset of ARDS in non-pulmonary sepsis.

Site of infection also appeared to be a risk modifier for ARDS in non-pulmonary sepsis. One study showed that abdominal infection was related to with ARDS [23], and another study showed that soft tissue infection was related to without ARDS in population that included pulmonary infection [13, 32]. The correlation with indirect ARDS in most previous studies may have been attenuated because pulmonary infection is a major predisposing condition and few studies focused on non-pulmonary infection $[2,14,15]$. We showed that, when excluding this, soft tissue infection could be related to having ARDS. Not only pulmonary but also severe soft tissue infection could be a novel risk modifier. However, these patients were more likely to be admitted to wards instead of ICUs, presumably because shock was less common [33]. By limiting our cohort to ICUs, we may have introduced some bias. It is possible that our data for site of infection reflect only disease severity, despite controlling for severity using the APACHE II score and shock status. Pathogens beyond the site of infection may also be related to having ARDS, but our sensitivity analysis did not show a difference (Additional file 1: Table S1). Further studies are needed to confirm which infection site is more related to developing ARDS in patients with non-pulmonary sepsis.

We confirmed that the severity of non-pulmonary sepsis (APACHE II score) was related to having ARDS, consistent with the results in previous studies $[2,11,13]$. In this study, we did not exclude the possibility of the pulmonary parameter of the APACHE II score representing pre-existing ARDS in the emergency department. Thus, we performed a sensitivity analysis by changing the APACHE II score with the non-pulmonary SOFA score, and it showed similar results to the main analysis (Additional file 1: Table S2). However, having shock was not related to having ARDS in our population, indicating that having ARDS in nonpulmonary sepsis might be associated with the development of multiple organ failure instead of circulatory failure (shock) [2, 31]. Further studies are needed to determine organ failures that are more likely to occur with ARDS.

We did not show roles for obesity, DM, statins, and glucocorticoids which have been shown to be risk modifiers for ARDS in previous studies. Although they were 
risk modifiers in direct and indirect ARDS combined, the tendencies of the ORs were similar. Otherwise, obesity may not be a risk modifier of ARDS due to nonpulmonary sepsis because of mechanism is not the same [23, 25]. DM, statin use, and glucocorticoid use have been protective against ARDS in some clinical and basic research [20, 21, 34], but this has not been carried through to randomized clinical trials [35-37] and we found no benefits associated with the regular use of these medications. However, it is perhaps the lack of significance for the roles of obesity and smoking that was most unexpected.

Obesity is considered a risk modifier for ARDS because patients with obesity need higher tidal volumes, positive end-expiratory pressures, and sufficiently high peak airway pressures to counter the pressure of their chest wall and abdomen [16, 38]. The lack of difference in this study may reflect our small sample size.

Smoking has also been clearly linked as a direct risk modifier in clinical studies $[17,18]$, which is known to occur through direct damage to the alveolar epithelium that leads to local inflammation [39, 40]. Despite this, our results did not support it even indirectly, and we consider there to be two main reasons. First, smoking history may have been difficult to assess in critically ill patients. Including a combination of smoking-related biomarkers might have identified more current smokers than the smoking history obtained from patients, surrogates, and medical records [41]. Second, unrecorded medication histories, including the use of inhaled corticosteroids and inhaled beta agonist may have been a confounding factor [42]. It is conceivable that smoking and indirect ARDS are not associated, as is the case with smoking and direct ARDS [23, 25]. Since it is difficult to consider smoking as a protective factor, we only used smoking as an adjustment factor in this study.

Risk modifiers for ARDS among patients with nonpulmonary sepsis were similar to those reported for patients with direct and indirect ARDS in previous studies, but they were not the same. This information may help clinicians and researchers. For clinicians, it is important to carefully treat non-pulmonary sepsis particularly in patients with risk modifiers that we have shown. For researchers, it may help to develop future study design and may provide more research on which to assess risks. We recommend that more classifications or adjustments are needed for ARDS because of the large heterogeneity in the syndrome.

\section{Limitations}

Several limitations of this study need to be acknowledged. First, we did not capture all ARDS episodes because we only performed screening on the first or fourth day. However, Most ARDS develops within 4 days of admission $[2,11,15]$ and most cases occur within $12 \mathrm{~h}$ if sepsis is a predisposing condition [43]. Second, we only included patients in ICUs, although it should be noted that most cases would have been admitted to ICUs anyway [2]. Third, there could be some unmeasured confounders because of the post hoc analysis, despite using mostly the same factors as in previous studies $[2,11$, 13]. Fourth, we diagnosed ARDS based on the application of the Berlin criteria by the physician in charge. Because the diagnosis of ARDS is difficult [44], some cases might not have been diagnosed correctly, even if they had respiratory failure. Fifth, we assessed risk modifiers at the first day of registration, yet we know that the value of some factors might be related to timing. However, risk modifier candidates were limited to patient backgrounds and characteristics, which were fixed at data collection. Sixth, based on the results of power analysis, the sample size of this study may not have been enough for the assessment of smoking and BMI as risk modifiers. Finally, our cohort was limited to Japan [2, $11,13]$, and important geographic variations may have been missed [45].

\section{Conclusions}

Our retrospective cohort study from the Japanese sepsis registry revealed that admission route, severity, and infection site could be risk modifiers for ARDS in patients with non-pulmonary sepsis.

\section{Supplementary information}

Supplementary information accompanies this paper at https://doi.org/10. 1186/s40560-020-0426-9.

Additional file 1: Table S1. Multivariable analysis including pathogens. Table S2. Multivariable analysis including Non-pulmonary SOFA score instead of APACHE II score. Two supplementary tables contain the results of sensitivity analyses indicated in the main manuscript.

\section{Abbreviations}

APACHE: Acute Physiology and Chronic Health Evaluation; ARDS: Acute respiratory distress syndrome; FORECAST: Focused Outcomes Research in Emergency Care in Acute Respiratory Distress Syndrome, Sepsis and Trauma; ICUs: Intensive care units; OR: Odds ratio

\section{Acknowledgments}

We thank the JAAM FORECAST Study Group for valuable contribution of this study

Investigators of JAAM FORECAST Study Group: Nagasaki University Hospital (Osamu Tasaki); Osaka City University Hospital (Yasumitsu Mizobata); Tokyobay Urayasu Ichikawa Medical Center (Hiraku Funakoshi); Aso lizuka Hospital (Toshiro Okuyama); Tomei Atsugi Hospital (Iwao Yamashita); Hiratsuka City Hospital (Toshio Kanai); National Hospital Organization Sendai Medical Center (Yasuo Yamada); Ehime University Hospital (Mayuki Aibiki); Okayama University Hospital (Keiji Sato); Tokuyama Central Hospital (Susumu Yamashita); Fukuyama City Hospital (Susumu Yamashita); JA Hiroshima General Hospital (Kenichi Yoshida); Kumamoto University Hospital (Shunji Kasaoka); Hachinohe City Hospital (Akihide Kon); Osaka City General Hospital (Hiroshi Rinka); National Hospital Organization Disaster Medical Center (Hiroshi Kato); University of Toyama (Hiroshi Okudera); Sapporo Medical University (Eichi Narimatsu); Okayama Saiseikai General Hospital (Toshifumi 
Fujiwara); Juntendo University Nerima Hospital (Manabu Sugita); National Hospital Organization Hokkaido Medical Center (Yasuo Shichinohe); Akita University Hospital (Hajime Nakae); Japanese Red Cross Society Kyoto Daini Hospital (Ryouji liduka); Maebashi Red Cross Hospital (Mitsunobu Nakamura); Sendai City Hospital (Yuji Murata); Subaru Health Insurance Society Ota Memorial Hospital (Yoshitake Sato); Fukuoka University Hospital (Hiroyasu Ishikura); Ishikawa Prefectural Central Hospital (Yasuhiro Myojo); Shiga University of Medical Science (Yasuyuki Tsujita); Nihon University School of Medicine (Kosaku Kinoshita); Seirei Yokohama General Hospital (Hiroyuki Yamaguchi); National Hospital Organization Kumamoto Medical Center (Toshihiro Sakurai); Saiseikai Utsunomiya Hospital (Satoru Miyatake); National Hospital Organization Higashi-Ohmi General Medical Center (Takao Saotome); National Hospital Organization Mito Medical Center (Susumu Yasuda); Tsukuba Medical Center Hospital (Toshikazu Abe); Osaka University Graduate School of Medicine (Hiroshi Ogura, Yutaka Umemura); Kameda Medical Center (Atsushi Shiraishi); Tohoku University Graduate School of Medicine (Shigeki Kushimoto); National Defense Medical College (Daizoh Saitoh); Keio University School of Medicine (Seitaro Fujishima, Junichi Sasaki); University of Occupational and Environmental Health (Toshihiko Mayumi); Kawasaki Medical School (Yasukazu Shiino); Chiba University Graduate School of Medicine (Taka-aki Nakada); Kyorin University School of Medicine (Takehiko Tarui); Kagawa University Hospital (Toru Hifumi); Tokyo Medical and Dental University (Yasuhiro Otomo); Hyogo College of Medicine (Joji Kotani); Saga University Hospital (Yuichiro Sakamoto); Aizu Chuo Hospital (Shin-ichiro Shiraishi); Kawasaki Municipal Kawasaki Hospital (Kiyotsugu Takuma); Yamaguchi University Hospital (Ryosuke Tsuruta); Center Hospital of the National Center for Global Health and Medicine (Akiyoshi Hagiwara); Osaka General Medical Center (Kazuma Yamakawa); Aichi Medical University Hospital (Naoshi Takeyama); Kurume University Hospital (Norio Yamashita); Teikyo University School of Medicine (Hiroto Ikeda); Rinku General Medical Center (Yasuaki Mizushima); Hokkaido University Graduate School of Medicine (Satoshi Gando)

\section{Authors' contributions}

$\mathrm{HI}$ conceived of and designed this study, interpreted the data, drafted the manuscript, and revised the manuscript for important intellectual content. TA contributed to the acquisition of data, conceived of and designed this study, interpreted the data, and revised the manuscript for important intellectual content. AS contributed to the acquisition of data, conducted data cleaning, interpreted the data, and revised the manuscript for important intellectual content. SK, HO, DS, SF, and TM, SG contributed to the acquisition of data, jointly conceived of and designed this study, interpreted the data, and revised the manuscript for important intellectual content. All authors contributed to the acquisition of data, reviewed, discussed, and approved the final manuscript.

\section{Funding}

This study was supported by the JAAM (2014-01).

\section{Availability of data and materials}

The datasets used and/or analyzed during the current study are available from the corresponding author on reasonable request.

\section{Ethics approval and consent to participate}

The study protocol was reviewed and approved by the ethics committee of all participating institutes in the Japanese Association for Acute Medicine (JAAM) study group. Institutional Review Board approval (No.014-0306) was obtained at Hokkaido University, the lead institution for FORECAST.

\section{Consent for publication}

Not applicable.

\section{Competing interests}

The authors declare that they have no competing interests.

\section{Author details}

'Department of General Medicine, Juntendo University, 2-1-1 Hongo, 103 Bunkyo-ku, Tokyo 113-0033, Japan. ${ }^{2}$ Health Services Research and Development Center, University of Tsukuba, Tsukuba, Japan. ${ }^{3}$ Department of Health Services Research, Faculty of Medicine, University of Tsukuba, Tsukuba, Japan. ${ }^{4}$ Division of Emergency and Critical Care Medicine, Tohoku University
Graduate School of Medicine, Sendai, Japan. ${ }^{5}$ Center for General Medicine Education, Keio University School of Medicine, Tokyo, Japan. ${ }^{6}$ Department of Traumatology and Acute Critical Medicine, Osaka University Graduate School of Medicine, Suita, Japan. ${ }^{7}$ Emergency and Trauma Center, Kameda Medical Center, Kamogawa, Japan. ${ }^{8}$ Division of Traumatology, Research Institute, National Defense Medical College, Tokyo, Japan. ${ }^{9}$ Department of Emergency Medicine, School of Medicine, University of Occupational and Environmental Health, Kitakyushu, Japan. ${ }^{10}$ Department of Emergency and Critical Care Medicine, St. Luke's International Hospital, Tokyo, Japan. ${ }^{11}$ Department of Acute Medicine, Kawasaki Medical School, Kurashiki, Japan. ${ }^{12}$ Department of Emergency and Critical Care Medicine, Chiba University Graduate School of Medicine, Chiba, Japan. ${ }^{13}$ Department of Trauma and Critical Care Medicine, Kyorin University School of Medicine, Mitaka, Japan. ${ }^{14}$ Trauma and Acute Critical Care Center, Medical Hospital, Tokyo Medical and Dental University, Tokyo, Japan. ${ }^{15}$ Department of Surgery, Center for Gastroenterology and Liver Disease, Kitakyushu City Yahata Hospital, Kitakyushu, Japan.

${ }^{16}$ Department of Disaster and Emergency Medicine, Kobe University Graduate School of Medicine, Kobe, Japan. ${ }^{17}$ Emergency and Critical Care Medicine, Saga University Hospital, Saga, Japan. ${ }^{18}$ Department of Emergency and Critical Care Medicine, Keio University School of Medicine, Tokyo, Japan. ${ }^{19}$ Department of Emergency and Critical Care Medicine, Aizu Chuo Hospital, Aizuwakamatsu, Japan. ${ }^{20}$ Emergency \& Critical Care Center, Kawasaki Municipal Kawasaki Hospital, Kawasaki, Japan. ${ }^{21}$ Advanced Medical Emergency \& Critical Care Center, Yamaguchi University Hospital, Ube, Japan. ${ }^{22}$ Department of Emergency Medicine, Niizashiki Chuo General Hospital, Niiza, Japan. ${ }^{23}$ Division of Trauma and Surgical Critical Care, Osaka General Medical Center, Osaka, Japan. ${ }^{24}$ Department of Emergency and Critical Care Medicine, Nippon Medical School, Tokyo, Japan. ${ }^{25}$ Advanced Critical Care Center, Aichi Medical University Hospital, Nagakute, Japan. ${ }^{26}$ Advanced Emergency Medical Service Center, Kurume University Hospital, Kurume, Japan. ${ }^{27}$ Department of Emergency Medicine, Teikyo University School of Medicine, Tokyo, Japan. ${ }^{28}$ Department of Trauma, Critical Care Medicine, and Burn Center, Japan Community Healthcare Organization, Chukyo Hospital, Nagoya, Japan. ${ }^{29}$ Division of Acute and Critical Care Medicine, Hokkaido University Graduate School of Medicine, Sapporo, Japan. ${ }^{30}$ Department of Acute and Critical Care Medicine, Sapporo Higashi Tokushukai Hospital, Sapporo, Japan.

Received: 27 September 2019 Accepted: 1 January 2020

Published online: 10 January 2020

\section{References}

1. Hudson LD, Milberg JA, Anardi D, Maunder RJ. Clinical risks for development of the acute respiratory distress syndrome. Am J Respir Crit Care Med. 1995; 151:293-301.

2. Mikkelsen ME, Shah CV, Meyer NJ, Gaieski DF, Lyon S, Miltiades AN, et al. The epidemiology of acute respiratory distress syndrome in patients presenting to the emergency department with severe sepsis. Shock. 2013; 40:375-81.

3. Acute Respiratory Distress Syndrome Network, Brower RG, Matthay MA, Morris A, Schoenfeld D, Thompson BT, et al. Ventilation with lower tidal volumes as compared with traditional tidal volumes for acute lung injury and the acute respiratory distress syndrome. N Engl J Med. 2000;342:1301-8.

4. Brower RG, Lanken PN, Maclntyre N, Matthay MA, Morris A, Ancukiewicz M, et al. Higher versus lower positive end-expiratory pressures in patients with the acute respiratory distress syndrome. N Engl J Med. 2004;351:327-36.

5. National Heart, Lung, and Blood Institute Acute Respiratory Distress Syndrome (ARDS) Clinical Trials Network, Wiedemann HP, Wheeler AP, Bernard GR, Thompson BT, Hayden D, et al. Comparison of two fluidmanagement strategies in acute lung injury. N Engl J Med. 2006;354: 2564-75.

6. Martínez O, Nin N, Esteban A. Prone position for the treatment of acute respiratory distress syndrome: a review of current literature. Arch Bronconeumol. 2009:45:291-6.

7. Gattinoni L, Carlesso E, Taccone P, Polli F, Guérin C, Mancebo J. Prone positioning improves survival in severe ARDS: a pathophysiologic review and individual patient meta-analysis. Minerva Anestesiol. 2010;76:448-54.

8. Papazian L, Forel JM, Gacouin A, Penot-Ragon C, Perrin G, Loundou A, et al. Neuromuscular blockers in early acute respiratory distress syndrome. N Engl J Med. 2010;363:1107-16. 
9. Peek GJ, Mugford M, Tiruvoipati R, Wilson A, Allen E, Thalanany MM, et al. Efficacy and economic assessment of conventional ventilatory support versus extracorporeal membrane oxygenation for severe adult respiratory failure (Cesar): a multicentre randomised controlled trial. Lancet. 2009;374: 1351-63.

10. Levitt JE, Matthay MA. Clinical review: early treatment of acute lung injury-paradigm shift toward prevention and treatment prior to respiratory failure. Crit Care. 2012;16:223.

11. Gong MN, Thompson BT, Williams P, Pothier L, Boyce PD, Christiani DC. Clinical predictors of and mortality in acute respiratory distress syndrome: potential role of red cell transfusion. Crit Care Med. 2005;33:1191-8.

12. Ferguson ND, Frutos-Vivar F, Esteban A, Gordo F, Honrubia T, Peñuelas O, et al. Clinical risk conditions for acute lung injury in the intensive care unit and hospital ward: a prospective observational study. Crit Care. 2007;11:R96.

13. Seethala RR, Hou PC, Aisiku IP, Frendl G, Park PK, Mikkelsen ME, et al. Early risk factors and the role of fluid administration in developing acute respiratory distress syndrome in septic patients. Ann Intensive Care. 2017;7:11.

14. Trillo-Alvarez C, Cartin-Ceba R, Kor DJ, Kojicic M, Kashyap R, Thakur S, et al. Acute lung injury prediction score: derivation and validation in a population-based sample. Eur Respir J. 2011;37:604-9.

15. Gajic O, Dabbagh O, Park PK, Adesanya A, Chang SY, Hou P, et al. Early identification of patients at risk of acute lung injury: evaluation of lung injury prediction score in a multicenter cohort study. Am J Respir Crit Care Med. 2011;183:462-70.

16. Gong MN, Bajwa EK, Thompson BT, Christiani DC. Body mass index is associated with the development of acute respiratory distress syndrome. Thorax. 2010;65:44-50.

17. Calfee CS, Matthay MA, Kangelaris KN, Siew ED, Janz DR, Bernard GR, et al. Cigarette smoke exposure and the acute respiratory distress syndrome. Crit Care Med. 2015;43:1790-7.

18. Toy P, Bacchetti P, Grimes B, Gajic O, Murphy EL, Winters JL, et al. Recipient clinical risk factors predominate in possible transfusion-related acute lung injury. Transfusion. 2015;55:947-52.

19. Boyle AJ, Madotto F, Laffey JG, Bellani G, Pham T, Pesenti A, et al. Identifying associations between diabetes and acute respiratory distress syndrome in patients with acute hypoxemic respiratory failure: an analysis of the LUNG SAFE database. Crit Care. 2018;22:268.

20. Peter JV, John P, Graham PL, Moran JL, George IA, Bersten A. Corticosteroids in the prevention and treatment of acute respiratory distress syndrome (ARDS) in adults: meta-analysis. BMJ. 2008;336:1006-9.

21. Jacobson JR, Barnard JW, Grigoryev DN, Ma SF, Tuder RM, Garcia JG. Simvastatin attenuates vascular leak and inflammation in murine inflammatory lung injury. Am J Physiol Lung Cell Mol Physiol. 2005;288: L1026-32.

22. Shyamsundar M, McKeown ST, O'Kane CM, Craig TR, Brown V, Thickett DR, et al. Simvastatin decreases lipopolysaccharide-induced pulmonary inflammation in healthy volunteers. Am J Respir Crit Care Med. 2009;179: 1107-14.

23. Sheu CC, Gong MN, Zhai R, Bajwa EK, Chen F, Thompson BT, et al. The influence of infection sites on development and mortality of ARDS. Intensive Care Med. 2010;36:963-70.

24. Levitt JE, Bedi H, Calfee CS, Gould MK, Matthay MA. Identification of early acute lung injury at initial evaluation in an acute care setting prior to the onset of respiratory failure. Chest. 2009;135:936-43.

25. Calfee CS, Janz DR, Bernard GR, May AK, Kangelaris KN, Matthay MA, et al. Distinct molecular phenotypes of direct vs indirect ARDS in single-center and multicenter studies. Chest. 2015;147:1539-48.

26. Abe T, Ogura H, Shiraishi A, Kushimoto S, Saitoh D, Fujishima S, et al. Characteristics, management, and in-hospital mortality among patients with severe sepsis in intensive care units in Japan: the FORECAST study. Crit Care. 2018;22:322

27. ARDS Definition Task Force, Ranieri VM, Rubenfeld GD, Thompson BT, Ferguson ND, Caldwell $E$, et al. Acute respiratory distress syndrome: the Berlin Definition. JAMA. 2012;307:2526-2533.

28. Levy MM, Fink MP, Marshall JC, Abraham E, Angus D, Cook D, et al. 2001 SCCM/ESICM/ACCP/ATS/SIS international sepsis definitions conference. Crit Care Med. 2003;31:1250-6.

29. Girard TD, Kress JP, Fuchs BD, Thomason JW, Schweickert WD, Pun BT, et al. Efficacy and safety of a paired sedation and ventilator weaning protocol for mechanically ventilated patients in intensive care
(Awakening and Breathing Controlled trial): a randomised controlled trial. Lancet. 2008;371:126-34.

30. Kanda Y. Investigation of the freely available easy-to-use software 'EZR' for medical statistics. Bone Marrow Transplant. 2013;48:452-8.

31. Nam H, Jang SH, Hwang Yl, Kim JH, Park JY, Park S. Nonpulmonary risk factors of acute respiratory distress syndrome in patients with septic bacteraemia. Korean J Intern Med. 2019;34:116-24.

32. Fujishima S, Gando S, Daizoh S, Kushimoto S, Ogura H, Mayumi T, et al. Infection site is predictive of outcome in acute lung injury associated with severe sepsis and septic shock. Respirology. 2016;21:898-904.

33. Abe T, Ogura H, Kushimoto $S$, Shiraishi A, Sugiyama T, Deshpande GA, et al. Variations in infection sites and mortality rates among patients in intensive care units with severe sepsis and septic shock in Japan. J Intensive Care. 2019;7:28.

34. Moss M, Guidot DM, Steinberg KP, Duhon GF, Treece P, Wolken R, et al. Diabetic patients have a decreased incidence of acute respiratory distress syndrome. Crit Care Med. 2000;28:2187-92.

35. Annane D, Sébille V, Bellissant E, Ger-Inf-05 Study Group. Effect of low doses of corticosteroids in septic shock patients with or without early acute respiratory distress syndrome. Crit Care Med. 2006:34:22-30.

36. McAuley DF, Laffey JG, O'Kane CM, Perkins GD, Mullan B, Trinder TJ, et al. Simvastatin in the acute respiratory distress syndrome. N Engl J Med. 2014; 371:1695-703

37. National Heart, Lung, and Blood Institute ARDS Clinical Trials Network, Truwit JD, Bernard GR, Steingrub J, Matthay MA, Liu KD, et al. Rosuvastatin for sepsis-associated acute respiratory distress syndrome. N Engl J Med. 2014;370:2191-200.

38. O'Brien JM Jr, Welsh CH, Fish RH, Ancukiewicz M, Kramer AM, National Heart, Lung, and Blood Institute Acute Respiratory Distress Syndrome Network, et al. Ann Intern Med. 2004;140:338-45.

39. Hirsch J, Chalkley RJ, Bentley T, Burlingame AL, Frank JA. Double impact of cigarette smoke and mechanical ventilation on the alveolar epithelial type ॥ cell. Crit Care. 2014;18:R50.

40. Checa M, Hagood JS, Velazquez-Cruz R, Ruiz V, García-De-Alba C, RangelEscareño $C$, et al. Cigarette smoke enhances the expression of profibrotic molecules in alveolar epithelial cells. Plos One. 2016;11:e0150383.

41. Hsieh SJ, Ware LB, Eisner MD, Yu L, Jacob P 3rd, Havel C, et al. Biomarkers increase detection of active smoking and secondhand smoke exposure in critically ill patients. Crit Care Med. 2011;39:40-5.

42. Festic E, Carr GE, Cartin-Ceba R, Hinds RF, Banner-Goodspeed V, Bansal V, et al. Randomized clinical trial of a combination of an inhaled corticosteroid and beta agonist in patients at risk of developing the acute respiratory distress syndrome. Crit Care Med. 2017:45:798-805.

43. Iscimen R, Cartin-Ceba R, Yilmaz M, Khan H, Hubmayr RD, Afessa B, et al. Risk factors for the development of acute lung injury in patients with septic shock: an observational cohort study. Crit Care Med. 2008;36:1518-22.

44. Bellani G, Laffey JG, Pham T, Fan E, Brochard L, Esteban A, et al. Epidemiology, patterns of care, and mortality for patients with acute respiratory distress syndrome in intensive care units in 50 countries. JAMA. 2016;315:788-800.

45. Villar J, Blanco J, Añón JM, Santos-Bouza A, Blanch L, Ambrós A, et al. The ALIEN study: incidence and outcome of acute respiratory distress syndrome in the era of lung protective ventilation. Intensive Care Med. 2011;37:1932-41.

\section{Publisher's Note}

Springer Nature remains neutral with regard to jurisdictional claims in published maps and institutional affiliations.

\section{Ready to submit your research? Choose BMC and benefit from:}

- fast, convenient online submission

- thorough peer review by experienced researchers in your field

- rapid publication on acceptance

- support for research data, including large and complex data types

- gold Open Access which fosters wider collaboration and increased citations

- maximum visibility for your research: over $100 \mathrm{M}$ website views per year

At BMC, research is always in progress.

Learn more biomedcentral.com/submissions 